\title{
Time-Varying Betas Help in Asset Pricing: The Threshold CAPM
}

\author{
Levent Akdeniz* \\ Aslıhan Altay Salih** \\ Mehmet Caner ${ }^{* * *}$
}

December 2002

* Bilkent University, Ankara, Turkey, Phone: +90 (312) 2902202 email: akdeniz@bilkent.edu.tr ** Bilkent University, Ankara, Turkey, Phone: +90 (312) 2902047 email: asalih@bilkent.edu.tr *** University of Pittsburgh, , email: caner+@pitt.edu

The authors thank Eric Ghysels for providing the data set and Lutz Kilian and Angelo Melino for their useful comments. Caner acknowledges the support from the University of Pittsburgh Central Research Development Fund. 
Time-Varying Betas Help in Asset Pricing:

The Threshold CAPM 


\begin{abstract}
Although there is a consensus about time variation in market betas, it is not clear how this variation should be captured. Several researchers continue to analyze different versions of the conditional CAPM. However, Ghysels (1998) shows that these conditional CAPM models fail to capture the dynamics of beta risk. In this study, we introduce a new model, threshold CAPM, which outperforms both the conditional and unconditional CAPMs by generating smaller pricing errors. We also show that the beta risk changes through time with the changes in the economic environment and the dynamics of time variation of beta differ across industries. These findings have important implications for asset allocation, portfolio selection, and hedging decisions.
\end{abstract}




\section{INTRODUCTION}

The Capital Asset Pricing Model (CAPM) of Sharpe (1964), Lintner (1965), and Black (1972) has constituted one of the cornerstones of modern finance theory for the last four decades. The CAPM posits a simple and stable linear relationship between an asset's systematic risk and its expected return. However, recent studies, notably Banz (1981), Basu (1983), Bhandari (1988), and Fama and French (1992), have found weak or no statistical evidence in support of this simple relationship. Stimulated by these findings, a number of researchers have sought to find alternative explanations for the risk and return trade off. One line of attack has been that of Fama and French $(1993,1995)$ who concluded that fundamental variables, namely Book-to-Market equity ratio and Market Equity, found to explain the variation in returns must be proxies for some unidentified risk factors. Another line has been advocated by Ferson (1989), Ferson and Harvey (1991, 1993), Ferson and Korajczyk (1995), and Jaganathan and Wang (1996), who argue that beta and market risk premium vary over time, therefore, static CAPM should be improved by incorporating time variation in beta in the model.

Although there is now considerable empirical evidence on time variation in betas, it is not clear how this variation should be captured. Many researchers ${ }^{1}$ model the variation in betas using continuous approximation and the theoretical framework of the conditional CAPM. However, Ghysels (1998) shows that this approximation fails to capture the dynamics of beta risk. He argues that betas change through time very slowly and linear factor models like the conditional CAPM may have a tendency to overstate the time variation. Thus, they produce time variation in beta that is highly volatile, leading to large pricing errors. He concludes that it is better to use the static 
CAPM in pricing, as we do not have a proper model that captures time variation in betas correctly.

Empirically documented large pricing errors could be due to the linear approach used in the above models. Treating a non-linear relationship as a linear one can lead to serious prediction problems in estimation. Thus, we first test for the existence of significant evidence of non-linearity in the time series relationship of industry returns with market returns using sup-LM test of Hansen (1996). Our findings exhibit that there exists statistically significant non-linearity in this relationship with respect to real interest rates. Bansal and Viswanathan (1993) also documents a similar nonlinearity of returns with respect to market risk and interest rates. Nevertheless, there are very few non-linear asset-pricing models in the finance literature, as they are cumbersome to analyze and interpret. In this paper we take a nonlinear approach to estimate betas over time, as we believe that acknowledging the non-linearity is an important step towards capturing the dynamics of beta. Along these lines we benefit from Hansen's (2000) threshold regression framework. The threshold regression theory has gained a lot of momentum recently, for some of the selected studies in this literature see Hansen (2000), Caner and Hansen (2001), Gonzalo and Pitarakis (2001), Gonzalo and Gonzales (1998), Chan (1993) and Chan and Tsay (1998).

In this study, we propose a new version of conditional CAPM; threshold CAPM . The threshold CAPM is a simple and intuitive nonlinear model. It captures the slow variation in betas and allows betas to respond to the changes in the economic environment. We model the market risk as a function of an underlying economic variable which we call threshold variable. The model allows beta to change when the 
threshold variable hits a certain threshold level thus it allows for two different beta regimes. $^{2}$ In order to capture slowly changing nature of market risk ${ }^{3}$ threshold CAPM treats beta to be constant for certain ranges of the threshold variable. We think that, this way of modeling the dynamics of beta is a good approximation for a slowly changing continuous beta. To verify this point, we perform a forecasting exercise same as in Ghysels (1998) and compared pricing errors of threshold CAPM with unconditional CAPM, conditional CAPM, and conditional APT. Threshold CAPM generates much smaller pricing errors.

In this paper we also statistically test the existence of time variation in market risk due to the threshold variable. Our findings document that there exist shifts in the betas associated with the threshold variables. Then we estimate the value of an economic variable that indicates a change in the economic conditions along with the corresponding values of betas. Our framework enables us not only to estimate different risk characteristics for various industries during different economic conditions but also estimate the level of an economic variable that causes the regime change.

The outline of the paper is as follows; section 2 introduces the methodology; section 3 explains our data set and empirical results and section 4 concludes the paper.

\section{METHODOLOGY}

\section{A. Threshold CAPM}

We begin with a very basic version of the conditional CAPM; 


$$
E\left[r_{t+1} \mid Z_{t}\right]=\beta_{t} E\left[r_{t+1} \mid Z_{t}\right],
$$

where $\beta_{\mathrm{t}}$ is the parameterised time varying beta, $\mathrm{rm}_{\mathrm{t}+1}$ represents the excess return from $t$ to $t+1$ on the market portfolio, $r_{t+1}$ is the excess return on any asset or portfolio of assets, and $Z_{t}$ is a set of instruments.

We use a similar specification of conditional CAPM suggested by Ferson and Harvey (1999), and we model time varying beta as

$$
\beta_{\mathrm{t}}=\beta_{1} 1_{\left\{\mathrm{z}_{\mathrm{t}} \leq \lambda\right\}}+\beta_{2} 1_{\left\{\mathrm{z}_{\mathrm{t}}>\lambda\right\}}
$$

where $1_{\}}$is the indicator function and $\lambda$ is the threshold parameter. When we combine (1)-(2) we have the following threshold CAPM equation:

$r_{t+1}=\left(\beta_{1} 1_{\left\{Z_{\mathrm{t}} \leq \lambda\right\}}+\beta_{2} 1_{\left\{\mathrm{Z}_{\mathrm{t}}>\lambda\right\}}\right) \mathrm{rm}_{\mathrm{t}+1}+\mathrm{e}_{\mathrm{t}+1}$

where $e$ is the error term. We call $Z_{\mathrm{t}}$ threshold variable. Market return and error terms are uncorrelated over time.

\section{B. Econometric Model}

The observed sample is $\left\{\mathrm{r}_{\mathrm{t}}, \mathrm{rm}_{\mathrm{t}}, \mathrm{Z}_{\mathrm{t}}\right\}, \mathrm{t}=1, \ldots ., \mathrm{T}$. The random variables $\mathrm{r}_{\mathrm{t}}, \mathrm{rm}_{\mathrm{t}}$, and $\mathrm{Z}_{\mathrm{t}}$ are real valued. The threshold variable $Z_{t}$ is assumed to have a continuous distribution. Threshold regression has the same format as in equation (3). 
We can rewrite equation (3) in the following form;

$$
r_{t+1}=\theta^{\prime} x_{t+1}+\delta^{\prime} x_{t+1}(\lambda)+e_{t+1}
$$

where $x_{\mathrm{t}+1}=\mathrm{rm}_{\mathrm{t}+1}, x_{t+1}(\lambda)=x_{t+1} 1_{\left\{z_{t} \leq \lambda\right\}}, \theta=\beta_{2}$ and $\delta=\beta_{1}-\beta_{2}$.

The results can be generalized to the case where only a sub set of parameters switch between the regimes and to the case where some regressors only enter in one of the two regimes. Also, $\lambda$ takes values in a bounded subset of the real line: $\Gamma$.

\section{Assumptions: (Hansen (2000))}

1) $\left[\mathrm{r}_{\mathrm{m}}, \mathrm{Z}_{\mathrm{t}}, \mathrm{e}_{\mathrm{t}}\right]$ are strictly stationary ergodic and $\rho$-mixing with $\rho$-mixing coefficients satisfying $\sum \rho_{\mathrm{m}}{ }^{1 / 2}<\infty$.

2) $\quad \mathrm{E}\left[\mathrm{e}_{\mathrm{t}} \mid \mathrm{Z}_{\mathrm{t}-1}\right]=0$

3) $\quad \mathrm{E}\left|\mathrm{r}_{\mathrm{mt}}\right|^{4}<\infty, \mathrm{E}\left|\mathrm{r}_{\mathrm{mt}} \mathrm{e}_{\mathrm{t}}\right|^{4}<\infty$.

4) for all $\lambda \in \Gamma, E\left[\mathrm{r}_{\mathrm{mt}}{ }^{4} \mathrm{e}_{\mathrm{t}}{ }^{4} \mid \mathrm{Z}_{\mathrm{t}}=\lambda\right] \leq \mathrm{C}, \mathrm{E}\left[\mathrm{r}_{\mathrm{mt}}{ }^{4} \mid \mathrm{Z}_{\mathrm{t}}=\lambda\right] \leq \mathrm{C}$ for some $\mathrm{C}<\infty$ and $\mathrm{f}(\lambda) \leq \overline{\mathrm{f}}<\infty$ where $f($.$) is the density function of Z_{t}$.

5) $\quad \mathrm{E}\left[\mathrm{r}_{\mathrm{mt}}^{2} \mid \mathrm{Z}_{\mathrm{t}}=\lambda\right]$ and $\mathrm{E}\left[\mathrm{r}_{\mathrm{mt}}^{2} \mathrm{e}_{\mathrm{t}}^{2} \mid \mathrm{Z}_{\mathrm{t}}=\lambda\right]$ is continuous at $\lambda=\lambda_{0}$ where $\lambda_{0}$ is the true value of threshold.

6) $\delta_{\mathrm{T}}=\mathrm{c} \mathrm{T}^{-\alpha}$ with $\mathrm{c} \neq 0,0<\alpha<1 / 2$

7) $\quad c^{\prime} E\left[r_{m t}^{2} \mid Z_{t}=\lambda_{0}\right] c>0$ and $c^{\prime} E\left[r_{m t}^{2} e_{t}^{2} \mid Z_{t}=\lambda_{0}\right] c>0$ and $f\left(\lambda_{0}\right)>0$.

8) $\mathrm{E}\left[\mathrm{r}_{\mathrm{mt}}^{2} 1_{[\mathrm{Zt} \leq \lambda]]}>0\right.$ for all $\lambda \in \Gamma$.

Assumption 1 excludes time trends, integrated processes and long memory processes. Assumption 2 shows the correct specification of the conditional mean. Assumption 5 
excludes regime dependent heteroskedasticity. Assumption 6 specifies that difference in regression slopes gets smaller as the sample size increases. This helps us in getting a nuisance parameter free limit distribution. However, this assumption is not needed for building confidence intervals and assumption 7 is a full rank condition which is needed to have non-degenerate asymptotic distributions.

We assume $r_{m}, Z_{t}$, and $e_{t}$ are strictly stationary ergodic and $\rho$-mixing with $\rho$-mixing coefficients satisfying $\sum \rho_{\mathrm{m}}{ }^{1 / 2}<\infty$. The $\rho$-mixing assumption controls the degree of time series dependence and allows the processes to be autocorrelated and heteroskedastic. The $\rho$-mixing assumption is sufficiently flexible to embrace many non-linear time series processes including threshold autoregressions. ${ }^{4}$

\section{B.1. Testing for a Threshold}

We use the heteroskedasticity consistent Lagrange Multiplier (LM) test for a threshold as in Hansen (1996). We test for the null of

$$
\begin{aligned}
& \mathrm{H}_{0}: \delta=0 \text { against } \\
& \mathrm{H}_{1}: \delta \neq 0
\end{aligned}
$$

For all $\lambda \in \Gamma$ we have the following LM statistics for the null of no threshold. 
$\operatorname{LM}_{\mathrm{T}}(\lambda)=\mathrm{T}[\mathrm{R} \hat{\gamma}(\lambda)]^{\prime}\left[\mathrm{R}_{\mathrm{T}}^{*}(\lambda) \mathrm{R}^{\prime}\right]^{-1}[\mathrm{R} \hat{\gamma}(\lambda)]$

where $\mathrm{R}=[0, \mathrm{I}], \hat{\gamma}(\lambda)=\left[\hat{\theta}(\lambda)^{\prime}, \hat{\delta}(\lambda)^{\prime}\right]^{\prime}$

$$
\begin{aligned}
& \hat{\gamma}(\lambda)=\left[\sum_{t=1}^{T} x_{t+1}^{*}(\lambda) x_{t+1}^{*}(\lambda)^{\prime}\right]^{-1}\left[\sum_{t=1}^{T} x_{t+1}^{*}(\lambda) r_{t+1}\right] \\
& x_{t+1}^{*}(\lambda)=\left[x_{t+1}, x_{t+1}(\lambda)\right] \\
& \hat{V}_{T}^{*}(\lambda)=M_{T}(\lambda)^{-1} \widetilde{V}_{T}(\lambda) M_{T}(\lambda)^{-1} \\
& M_{T}(\lambda)=\frac{1}{T} \sum_{t=1}^{T} x_{t+1}^{*}(\lambda) x_{t+1}^{*}(\lambda)^{\prime} \\
& \tilde{V}_{T}(\lambda)=\frac{1}{T} \sum_{t=1}^{T} x_{t+1}^{*}(\lambda) x_{t+1}^{*}(\lambda)^{\prime} \widetilde{e}_{t+1}^{2}
\end{aligned}
$$

$\widetilde{\mathrm{e}}_{\mathrm{t}}$

is obtained from the restricted least squares. Unfortunately, the large sample limit for sup-LM test is not nuisance free, since the threshold is not identified under the null of no threshold effect. So Hansen (1996) suggests a bootstrap analog of the sup-LM test. Hansen (1996) shows that this bootstrap method yields asymptotically correct p-values. The bootstrap analog consists of the following steps;

1) $\quad$ Form $\operatorname{LM}_{T}(\lambda)$ for each $\lambda \in \Gamma$

2) Select the largest $\operatorname{LM}_{\mathrm{T}}(\lambda)$ among them and call this $\operatorname{LM}_{\mathrm{T}}{ }^{*}(\lambda)$.

3) Then generate the dependent variable for the bootstrap in the following way; multiply a standard normal random vector of $\mathrm{T}$ observations cell by cell with the residuals from the Restricted Least Squares regression. This gives us in our case $r_{b}$

4) Then calculate $\mathrm{LM}_{\mathrm{T}}{ }^{\mathrm{b}}(\lambda)$ with fixed regressors and $\mathrm{r}_{\mathrm{b}}$ as the dependent variable.

5) Select the largest $\operatorname{LM}_{\mathrm{T}}^{\mathrm{b}}(\lambda)$ and call it $\operatorname{LM}_{\mathrm{T}}{ }^{\mathrm{b}}(\lambda)$ 
6) Generate 1000 bootstrap replications of $\mathrm{LM}_{\mathrm{T}}{ }^{\mathrm{b}^{*}}(\lambda)$, which is repeating steps 3 to 51000 times.

7) $\quad$-value is the percentage of $\operatorname{LM}_{\mathrm{T}}{ }^{\mathrm{b}}(\lambda)$ exceeding $\operatorname{LM}_{\mathrm{T}}{ }^{*}(\lambda)$.

\section{B.2. Estimation}

In this section, we estimate the unknown threshold parameter $\lambda$, however we slightly change the model to have

$$
r_{t+1}=\theta^{\prime} x_{t+1}+\delta_{T}^{\prime} x_{t+1}(\lambda)+e_{t+1} \quad \mathrm{t}=1, \ldots \ldots, \mathrm{T}
$$

where $\delta_{\mathrm{T}}$ is the "threshold effect". We let $\delta_{\mathrm{T}} \rightarrow 0$ as T $\rightarrow \infty$ (See Hansen (2000) sections 1 and 5 for details) in order to have a nuisance parameter free asymptotic distribution. However, confidence intervals for $\lambda$ can be built even when the threshold effect does not decrease with the sample size. We can rewrite (5) in a matrix form where $\mathrm{X}$ and $\mathrm{X}_{\lambda}$ are $\mathrm{T} \times 2$ matrices and $\mathrm{R}$ is a $\mathrm{T} x 1$ vector.

$$
R=X \theta+X_{\lambda} \delta_{T}+e
$$

We use LS estimation as in Hansen (2000, section 2):

$$
S_{T}(\theta, \delta, \lambda)=\left(R-X \theta-X_{\lambda} \delta\right)^{\prime}\left(R-X \theta-X_{\lambda} \delta\right)
$$

where $\mathrm{S}_{\mathrm{T}}$ is the sum of squared errors. To estimate slope parameters and the threshold parameter, we observe that first given $\lambda$, equation (5) is linear in $\theta$ and $\delta_{\mathrm{T}}$. We can 
have the conditional LS estimates $\hat{\theta}(\lambda)$ and $\hat{\delta}_{\mathrm{T}}(\lambda)$ by regressing $\mathrm{Y}$ on $\left[\mathrm{X} \mathrm{X}_{\lambda}\right]$. Then set

$$
\mathrm{S}_{\mathrm{T}}(\lambda)=\mathrm{S}_{\mathrm{T}}(\hat{\theta}(\lambda), \hat{\delta}(\lambda), \lambda)
$$

The estimate of threshold parameter $\hat{\lambda}$ can be uniquely defined as

$$
\hat{\lambda}=\operatorname{argmin} \mathrm{S}_{\mathrm{T}}(\lambda)
$$

where $\lambda$ is minimised over the set $\Gamma_{\mathrm{T}}=\Gamma \cap\left\{\mathrm{Z}_{1}, \ldots \ldots, \mathrm{Z}_{\mathrm{T}}\right\}$. So $\hat{\lambda}$ can be derived by less than $\mathrm{T}$ function evaluations. Then slope estimates can be computed by plugging in $\hat{\lambda}$ into $\hat{\theta}(\lambda)$ and $\hat{\delta}(\lambda)$, namely $\hat{\theta}(\hat{\lambda})$, and $\hat{\delta}(\hat{\lambda})$. The asymptotic distribution for the threshold estimate $\hat{\lambda}$ follows from theorem 1 of Hansen (2000).

Proposition 1 (Hansen (2000)): Under assumption 1 - 7,

$$
\begin{aligned}
& \mathrm{T}^{1-2 \alpha}\left(\hat{\lambda}-\lambda_{0}\right) \rightarrow_{\mathrm{d}} \omega \mathrm{K}, \\
& \text { where } \omega=\frac{\mathrm{c}^{\prime} \mathrm{E}\left[\mathrm{r}_{\mathrm{mt}}^{2} \mathrm{e}_{\mathrm{t}}^{2} \mid \mathrm{Z}_{\mathrm{t}}=\lambda_{0}\right] \mathrm{c}}{\left[\mathrm{c}^{\prime} \mathrm{E}\left[\mathrm{r}_{\mathrm{mt}}^{2} \mid \mathrm{Z}_{\mathrm{t}}=\lambda_{0}\right] \mathrm{c}\right]^{2} \mathrm{f}} \\
& \qquad \mathrm{K}=\arg \max \left[-\frac{1}{2}|\mathrm{~s}|+\mathrm{W}(\mathrm{s})\right] \quad \text { where }-\infty<\mathrm{s}<\infty
\end{aligned}
$$

where $\mathrm{W}(\mathrm{s})$ is a two sided Brownian motion on the real line.

In proposition 1 the rate of convergence is $\mathrm{T}^{1-2 \alpha}$, this shows that a large $\alpha$ decreases threshold effect which reduces the precision of the estimator. The "small effect" asymptotics is similar to what is found in the "change point" literature. The distribution for $\mathrm{K}$ is known and it is shown in Hansen (2000). In order to build 
confidence intervals for the threshold parameter we invert the likelihood ratio test for testing $\mathrm{H}_{0}: \lambda=\lambda_{0}$. This test statistic has a nuisance free limit for details see Hansen (2000).

We use lemma A-12 of Hansen (2000) to establish the limit for the slope parameters. Set

$$
\underline{\theta}=(\theta, \delta)
$$

Then

Proposition 2: (Lemma A-12 Hansen (2000)) Under assumptions 1 - 7

$$
\mathrm{T}^{1 / 2}\left[\underline{\hat{\theta}}(\hat{\lambda})-\underline{\theta_{0}}\right\rfloor \rightarrow_{\mathrm{d}} \mathrm{N}\left(0, \mathrm{~V}_{\theta}\right)
$$

Where $V_{\theta}$ is the standard asymptotic covariance matrix if $\lambda=\lambda_{0}$ were fixed.

Basically this result shows that one can approximate the distribution of the slope parameters by the usual normal approximation as if $\lambda$ were known with certainty. For building confidence intervals see section 4 of Hansen (2000). An important part to note is that assumption 6 is not required for building confidence intervals, both for the slope and threshold parameter. The confidence intervals can be built where the threshold effect is constant as well (Theorem 3 Hansen (2000)). Note that we use heteroskedasticity robust confidence regions for our parameters.

\section{RESULTS}

\section{A. Data}

The data used in this study is the same data used in Ferson and Korajczk (1995) and Ghysels (1998). It covers monthly data from January 1927 to January 1988 on twelve industry portfolios of NYSE firms grouped by 2-digit SIC industry code. Names of these industries are reported in Table 1. For economic variables, we use one month real t-bill rate, dividend yield of the CRSP value-weighted NYSE stock index, detrended stock price level, measure of the slope of the term structure and quality related yield spread in the corporate bond market. We chose these variables as 
threshold variables because they are suggested by previous studies as predicting stock returns $^{5}$. Details of the data are in Ferson and Korajczyk (1995).

\section{B. Testing}

The first test explores the question of whether there are statistically significant discrete regime shifts in betas due to certain instrumental variables which are empirical proxies for changing economic environment. Table 2 reports the bootstrap p-values for the sup LM test used in Hansen (1996) which depict the likelihood of no regime shift. These values are reported for industry portfolios (January 1927 January 1988). As can be seen in Table 2, all of the twelve industry portfolios exhibit time variation in betas due to real interest rates at one percent significance level. We also observe similar findings for maturity spread; eight out of twelve industry portfolios exhibit time variation in betas at ten percent or below significance levels. However, for the other financial variables the evidence is mixed ${ }^{6}$. The econometric theory that underlies the threshold CAPM requires only one threshold variable. Therefore we concentrate only on one variable, namely interest rates ${ }^{7}$. For this purpose, we choose the variable that produces the lowest p-value across all industries. As it can be seen in Table 2, the threshold variable is real T-bill rate. Intuitively, real T-bill rate signals a regime shift in the strongest manner. Similar descriptive findings are documented in the literature by other studies such as Campbell and Mei (1993), Ferson (1989), and Jaganathan and Wang (1996).

As reported by Ghysels (1998), betas change through time very slowly. The conditional CAPM models may have a tendency to overstate the time variation. Therefore, they produce time variation in beta that is highly volatile and changing too rapidly. This is also confirmed with the evidence reported in Braun, Nelson and 
Sunier (1995), where they used bivariate EGARCH model to estimate conditional betas and found weak evidence of time variation in conditional betas. This explanation is also consistent with our findings. If a couple of significant changes exist in betas and the rest of the time they are more or less stable, continuous approximations of the CAPM will produce highly volatile beta estimates.

\section{Estimation}

In Table 3, we report betas and the threshold estimate of a inflation adjusted onemonth T-bill rate. Columns two and three show the values for betas in two regimes. Column four is the threshold estimates for one month real T-bill rate, and column five is the average betas estimated from the unconditional CAPM. As can be seen in Table 3, there are considerable shifts in the betas at different regimes in all twelve industries. For example, the Services Industry (Industry 11) possess a less risky nature with a beta value of 0.83 when the real interest rate is below $\% 3.5$; it becomes a riskier industry with a beta value of 1.32 when the real interest rate is above the estimated threshold level of \%3.5. However, if one ignores the time variation in beta and estimates the constant beta using unconditional CAPM at 0.95 , it is possible to make serious pricing errors. On the other hand, the Utilities Industry (Industry 9) depicts little time variation in betas under two regimes where the magnitude of the pricing error will be low.

In Table 3, we also observe that the shifts of the regimes in each industry are at different real interest rate levels which indicates that each industry responds to the fluctuations in interest rates differently. We notice that in ten out of twelve industries 
the threshold betas are higher in the high interest rate regimes than they are in low interest rate regimes. In only two industries we observe the opposite.

Betas and expected returns vary over time depending on the information about firm specific issues and overall economic conditions at any given point in time. As Jagannathan and Wang (1996) argues, time variation in beta may come from two different sources. During high interest rate periods highly leveraged firms are more likely to face financial problems so their betas are more likely to rise. At the same time, the decrease in the uncertainty about the growth prospects of firms can cause their betas to decrease. It is not immediately clear which cause will dominate. Hence betas might be higher or lower during high interest rate periods. It is also reasonable to expect fluctuations in the betas of different sectors in the economy due to sudden changes in technology or taste. In addition, some industries may be more capital intensive than others which makes them more sensitive to interest rates. Hence we do not expect betas of different sectors to respond to the changing economic conditions in the same way.

As mentioned earlier, our findings show that in most of the industries betas increase with increasing interest rates. Therefore because of the nature of the firms within those industries leverage effect dominates. Only in two industry groups the other effect dominates and the betas decrease with increasing interest rates. In order to understand these complex dynamics within each industry and firm, one would need a detailed analysis of the operating and financial positions of these firms within each industry, but it is far beyond the scope of the present paper. 
One may be tempted to explore the possibility of more regime shifts using the same methodology and partitioning the data into two groups according to the level of the threshold estimate. More specifically it is possible to collect those observations below the threshold estimate in one group, and those above the threshold estimate in another group, and then test for the existence of further regime shifts in these sub groups. However, the econometric theory of partitioning data in the applications of threshold models has not been established yet and smaller number of observations in sub periods may yield unreliable beta estimates.

\section{Forecasting}

In order to find the economic value of our findings to pricing, we calculate the pricing errors of threshold CAPM as described by equation (4) and compare them with the pricing errors of the unconditional CAPM, conditional CAPM and conditional APT reported in Gyhsels (1998). We used the following Root Mean Square Error formula to calculate the pricing errors of threshold CAPM.

Note that the comparisons of pricing errors does not include non-linear APT of Bansal and Viswanathan (1993). Prediction through non-linear APT requires a lot of additional assumptions thus, generating predictions of returns for forecasting purposes are nontrivial ${ }^{8}$.

The following moment conditions specify the unconditional CAPM in Ghysels (1998) 


$$
E\left(\begin{array}{l}
r m_{t+1}-Z_{t} \gamma m \\
r_{t+1}-\beta Z_{t} \gamma m
\end{array}\right) \otimes Z_{t}=0
$$

Where $\gamma \mathrm{m}$ is obtained from the following equation

$$
\mathrm{E}\left[\mathrm{rm}_{\mathrm{t}+1} \mid \mathrm{Z}_{\mathrm{t}}\right]=\gamma \mathrm{mZ} \mathrm{t}_{\mathrm{t}}
$$

The conditional CAPM models of Ferson and Harvey (1993) in Ghysels (1998) are specified by the following moment conditions

$$
E\left[\begin{array}{l}
\left(r_{t+1}-Z_{t} \gamma\right)^{\prime} \\
\left(r m_{t+1}-Z \gamma m\right)^{\prime} \\
\left(Z_{t} \gamma-Z_{t} \beta_{c} Z_{t} \gamma m\right)^{\prime}
\end{array}\right]^{\prime} \otimes Z_{t}^{\prime}=0
$$

where $\beta_{\mathrm{t}}=\mathrm{Z}_{\mathrm{t}} \beta_{\mathrm{c}}$ and $\gamma$ is defined as

$$
E\left[r_{t+1} \mid Z_{t}\right]=\gamma Z_{t}
$$

Multifactor conditional APT model of Ferson and Korajczyk (1995) in Ghysels (1998) is defined by the following moment conditions

$$
\mathrm{E}\left[\begin{array}{l}
\mathrm{r}_{\mathrm{it}+1}-\mathrm{Z}_{\mathrm{t}}^{\prime} \gamma_{\mathrm{i}} \\
\left(\mathrm{F}_{\mathrm{t}+1}^{\prime}-\mathrm{Z}_{\mathrm{t}}^{\prime} \gamma_{\mathrm{i}}\right)^{\prime} \\
\left(\mathrm{F}_{\mathrm{t}+1}^{\prime}-\mathrm{Z}_{\mathrm{t}}^{\prime} \gamma_{\mathrm{i}}\right)\left(\mathrm{F}_{\mathrm{t}+1}^{\prime}-Z_{\mathrm{t}}^{\prime} \gamma_{\mathrm{i}}\right)^{\prime} \beta_{\mathrm{i}}-\mathrm{F}_{\mathrm{t}+1}\left(\mathrm{r}_{\mathrm{it}+1}-\mathrm{Z}_{\mathrm{t}}^{\prime} \gamma_{\mathrm{i}}\right)
\end{array}\right] \otimes Z_{\mathrm{t}}^{\prime}=0
$$

where $F_{t}$ is a $K \times 1$ vector of factor mimicking portfolios, $\beta_{I}$ is a $K \times 1$ vector of the betas for asset $i$, and $Z_{t}$ is a $(L+1)$ vector of instruments. 
In-sample Root Mean Squared Errors (RMSE) of pricing errors for each model are reported in Table 5. The threshold CAPM produces much smaller pricing errors for all industries, thus outperforms the unconditional CAPM, conditional CAPMs, and multifactor conditional APT. In the case of Industry 4, the decrease in pricing errors goes up to $50 \%$.

There is now a consensus on time variation in market risk. The conditional CAPM is an attempt to capture this variation. However Ghysels (1998) shows that the conditional CAPM is unable to specify time variation accurately thus leads to higher pricing errors compared to the unconditional CAPM. In view of these findings, we believe that it is crucial to understand the dynamic of time variation in market risk and incorporate this dynamic in the pricing model. Our findings establish that the market risk is more or less stable under similar economic conditions but there are discrete shifts triggered by significant changes in the economic environment. Threshold CAPM is able to incorporate this time variation better than conditional CAPM. As a result, it leads to much lower pricing errors.

\section{CONCLUSION}

Many researchers agree that the CAPM is unable to explain the variation in expected stock returns. Stimulated by this inference, academicians have sought to find alternative solutions to the problem. One line of research has focused on improving the empirical application of the model by allowing time variation in beta using the 
conditional CAPM. However, Ghysels (1998) show that conditional CAPM is an inadequate solution for the problem as it produces higher pricing errors.

In this paper we show that changes that occur through time in the risk factor, beta, are associated with changes in the economic environment; the dynamic of time variation of beta differs across industries and; threshold CAPM outperforms both conditional and unconditional CAPMs since it produces much lower pricing errors.

Therefore, both the constant and the other time varying betas lead to serious errors in asset allocation, portfolio choice, and hedging.

For the future research, we plan to form a multifactor version of threshold CAPM. Another interesting line of research is to use a panel threshold model to capture the cross section of expected stock returns. However, the econometric theory of the panel threshold models is very limited at this point. 


\section{References}

Black, F. 1972, "Capital Market Equilibrium with Restricted Borrowing”, Journal of Business", 45, 444-455.

Bansal, R. and S. Wiswanathan, 1993, "No Arbitrage and Arbitrage Pricing: A New Approach" Journal of Finance, 47, 1231-1262

Banz, R. W, 1981. "The Relationship Between Securities' Yields and YieldSurrogates," Journal of Financial Economics, 9, 3-18.

Basu, S, 1983. 'The Relationship Between Earnings Yield, Market Value, and Return for NYSE Common Stocks: Further Evidence," Journal of Financial Economics, 12, 129-156.

Bhandari, L. C, 1988. "Debt/Equity Ratio and Expected Common Stock Returns: Empirical Evidence," Journal of Finance, 43, 507-528.

Braun, P. A., D. B. Nelson, and A. M. Sunier, 1995, "Good News, Bad News, Volatility and Betas", Journal of Finance, 50, 1575-1603.

Campbell, J. Y. and R. J. Shiller, 1988, "The Dividend Price Ratio and Expectations of Future Dividend and Discount Factors" Review of Financial Studies, 1, 195-228.

Campbell, J. Y and J. Mei, 1993, "Where Do Betas Come From? Asset Price Dynamics and the Sources of Systematic Risk", Review of Financial Studies, 6, 567 592.

Caner, M . and B.E. Hansen, 2001, “ Threshold Autoregressions with a Near Unit Root”, forthcoming Econometrica.

Chan, K.S. 1993, “Consistency and Limiting Distribution of the Least Squares Estimator of a Threshold Autoregressive Model", The Annals of Statistics, 21, 520 533.

Chan, K.S. and R. Tsay, 1998, “ Limiting Properties of the Least Squares Estimator of a Continuous Threshold Autoregressive Model”, Biometrika, 85, 413-426.

Chen, S. 1982 “An Examination of Risk Return Relationship in Bull and Bear Markets Using Time Varying Betas" Journal of Financial and Quantitative Analysis, $17,265-285$.

Davidson J., 1994, Stochastic Limit Theory, Oxford University Press, New York, NY.

Fabozzi, F. J. and J. C. Francis, 1977, "Stability Tests for Alphas and Betas Over Bull and Bear Market Conditions" Journal of Finance, 32, 1093-1099.

Fabozzi, F. J. and J. C. Francis,1979 "Mutual Fund Systematic Risk for Bull and Bear Markets: An Empirical Examination” Journal of Finance, 34, 1243-1250. 
Fama, E. and K. R. French, 1989, "Business Conditions and Expected Stock Returns" Journal of Financial Economics”, 25, 23-50

Fama, Eugene F, 1990 "Stock Returns, Expected Returns and Real Activity" Journal of Finance, 45, 1089-1108.

Fama, Eugene F. and G. W. Schwert, 1977, “Asset Returns and Inflation”, Journal of Financial Economics, 5, 115-146.

Fama, E. and K. R. French, 1992, "The Cross-Section of Expected Stock Returns" Journal of Finance, 47, 427-466.

Fama, E. and K. R. French, 1993, "Common Risk factors in the Returns on Bonds and Stocks", Journal of Financial Economics, 33, 3-56.

Fama, E. and K. R. French, 1995, "Size and Book-to-Market Factors in Earnings and Returns " Journal of Finance, 50, 131-155.

Ferson, W. E., 1989, "Changes in Expected Security Returns, Risk and the level of Interest Rates" Journal of Finance, 44, 1191-1214

Ferson, W. E. and C. R. Harvey, 1991, "The Time Variation of Economic Risk Premiums", Journal of Political Economy, 99, 385-415.

Ferson, W. E. and C. R. Harvey, 1993, "The Risk and Predictability of International Equity Returns", Review of Financial Studies, 6, 527-566

Ferson, W. E. and C. R. Harvey, 1999, "Conditioning Variables and the Cross Section of Stock Returns", Journal of Finance, Vol 54, No. 4, 1325-1360

Ferson, W. E. and R. A. Korajczyk, 1995, "Do Arbitrage Pricing Models Explain the Predictability of Stock Returns?”, Journal of Business, 68, 309-349.

Ghysels, E. 1998, "On Stable Factor Structures in the Pricing of Risk: Do Time Varying Betas Help or Hurt?”, Journal of Finance, 53, 549-573.

Gonzalo, J. and J. Y. Pitarakis, 2001, "Estimation and Model Selection Based Inference in Single and Multiple Threshold Models" Forthcoming Journal of Econometrics.

Gonzalo, J. and M. Gozales, 1998, "Threshold Unit Root Processes" Working Paper, University of Carlos III Madrid.

Granger, C. W. and P. Silvapulle, 2001 "Capital Asset Pricing Model, Bear, Usual and Bull Market Conditions and Beta Instability: A Value at Risk Approach" Working Paper, University of California, San Diego.

Hansen, B. E., 1996, "Inference When a Nuisance Parameter is not Identified Under the Null Hypothesis", Econometrica, 64, 413-430. 
Hansen, B. E., 2000, "Sample Splitting and Threshold Estimation", Econometrica, Vol 68, No 3, 575-605.

Jagannathan, R, and Z. Wang, 1996, "The Conditional CAPM and the Cross-Section of Expected Returns", Journal of Finance, 51, 3-53.

Keim, D. B. and R. F. Stambaugh, 1986, "Predicting Returns in the Bond and Stock Markets", Journal of Financial Economics, 17, 357-390.

Kim, M. K. and K. J. Zumwalt, 1979 "An Analysis of Risk in Bull and Bear Markets" Journal of Financial and Quantitative Analysis, 14, 1015-1025.

Lintner, J. 1965, "The Valuation of Risky Assets and the Selection of Risky Investments in Stock Portfolio and Capital Budgets", Review of Economics and Statistics, 47, 13-37.

Nefci, S. N. 1984, "Are Economic Time Series Asymmetric Over the Business Cycle?" The Journal of Political Economy, 92,307-328

Poterba, J. and L. Summers, 1988, "Mean Reversion in Stock Prices: Evidence and Implications" Journal of financial Economics, 22, 27-60

Sharpe, W. F. 1964, "Capital Asset Prices: A Theory Market Equilibrium under Conditions of Risk", Journal of Finance, 19, 425-442.

Woodward G. and H. Anderson, 2002, "Does Beta React to Market Conditions?: Estimates of Bull and Bear Betas Using a Nonlinear Market Model with Endogenous Threshold Prameter" Working Paper, Monash University. 


\section{End Notes}

${ }^{1}$ See Ferson and Harvey (1993), Jagannathan and Wang (1996)

${ }^{2}$ Nefci (1984) concludes that there is enough evidence in economic time series data to justify two different regimes during the business cycle.

${ }^{3}$ See Braun, Nelson and Sunier (1995) for a formal statistical test of this conjecture.

${ }^{4}$ For further information about $\rho$-mixing see Davidson (1994).

${ }^{5}$ Studies that document predictability using these variables are Fama and Schwert (1977), Ferson (1989), Campbell and Shiller (1988), Fama and French (1989), Poterba and Summers (1988), Keim and Stambaugh (1986) and Fama (1990)

${ }^{6}$ There is also a vast literature on beta dynamics over the states of the market. See Chen (1982), Fabozzi and Francis (1977,1979), Granger and Silvapulle (2001), Kim and Zumwalt (1979) and Woodward and Anderson (2002). The evidence on varying beta over the Bull and Bear markets is mixed. In our study we detect no variation in beta due to the detrended stock price level except for Industry 10, as documented in Table 2.

${ }^{7}$ Ferson (1989) also reports evidence on the significant relationship between conditional betas and interest rates.

${ }^{8}$ See Ghysels (1998) for a detailed explanation on the difficulties of prediction with pricing kernels. 